\title{
NEW YORK UNIVERSITY
}

\author{
MIDDLE EAST STUDIES ASSOCIATION BULLETIN
}

Vol. 2, No. 1, March 1, 1968

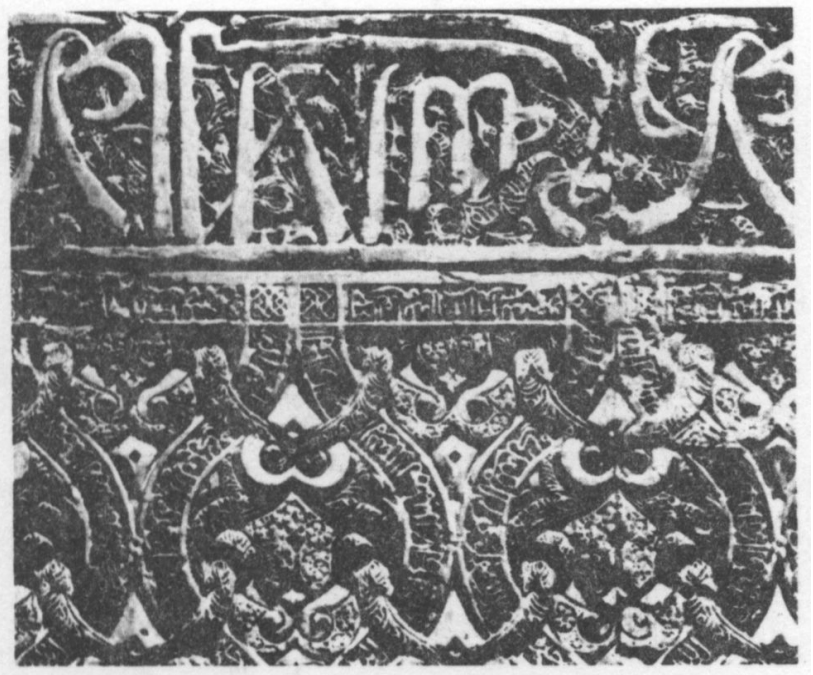

Middle East Studies Association of North America, Inc. Headquarters and Secretariat, New York University, Washington Square, New York, New York 10003 
MIDDLE EAST STUDIES ASSOCIATION BULLETIN

Vol. 2, No. 1, March 1, 1968

Middle East Studies Association of North America, Inc. Headquarters and Secretariat, New York University, Washington Square, New York, New York 10003 


\section{TABLE OF CONTENTS}

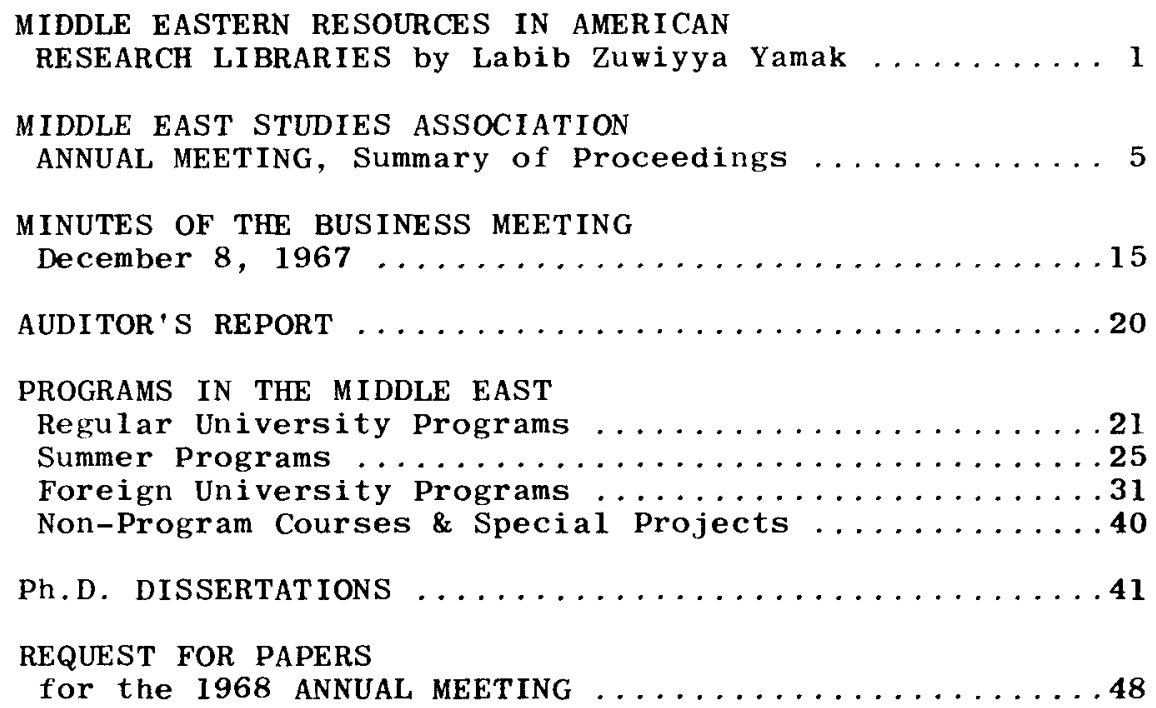

IMPORTANT ANNOUNCEMENTS

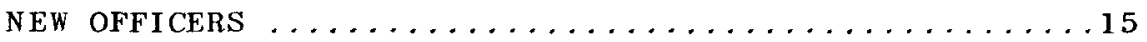

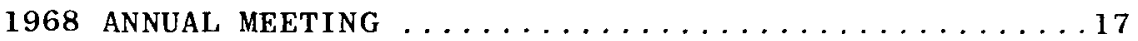

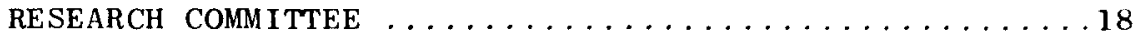

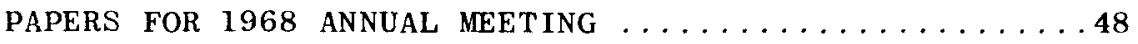

